\title{
Based on Flight Departure Queuing Problem for Terminal Area Capacity Assessment
}

\author{
Song Weiwei \\ Department of Civil Aviation \\ Shenyang Aerospace University \\ Liaoning, China \\ e-mail:wwsong1@126.com
}

\begin{abstract}
In recent years, along with the high-speed growth of national economy, the total turnover of scheduled air transportation in China has risen to number five and passenger turnover rose to Number four in the world. Flight departure queuing occurs mainly in the terminal control area and this is an important part for causing flight delays. To improve the effectiveness of assessment for the departure flight which in the terminal control area, according to the air traffic flow queuing feature, considering estimate departure time, apron, wake turbulence, adopting an algorithm with improved first come first serve to build simulation models to assess the simulation situation for reducing flight delays. Take an example of terminal area of Wuhan Tianhe International Airport, it chooses a flight plan of one day to simulate the daily operation. Simulation results show that using first come first serve algorithm for departure flight can reduce delays, increase airport capacity and improve runway utilization.
\end{abstract}

Keywords-terminal area; departure flight; aircraft; capacity evaluation; queue

\section{INTRODUCTION}

Terminal area airspace ${ }^{[1]}$ is in the interchange of the approach and departure routes and traffic congestion problems highlight, so this part is the key implementation elements of traffic management. To assess the capacity of terminal area, understanding its capacity limit is the basis for traffic management ${ }^{[2]}$. For single-sector terminal airspace, we can resolve this problem by changing the sector controller workload constraints into sectors traffic flow constraints ${ }^{[3-4]}$. According to the traffic flow queuing feature, considering estimate departure time, apron, wake turbulence, adopting an algorithm with improved first come first serve, building simulation models to assess the simulation situation for reducing flight delays. Take an example of terminal area of Wuhan Tianhe International Airport, choosing flight plan of a day to simulate the daily operation. Simulation results show that using first come first serve algorithm for departure flight can reduce delays, increase airport capacity and improve runway utilization.

\section{THE DESIGN OF FLIGHT DEPARTURE QUEUE SYSTEM}

\section{A. The relative presentation for flight departure queue}

Flight departure ${ }^{[5-6]}$ will go through five stages and complete departure which need to according to specified departure procedures under air traffic controller. It will be shown in Fig.1.

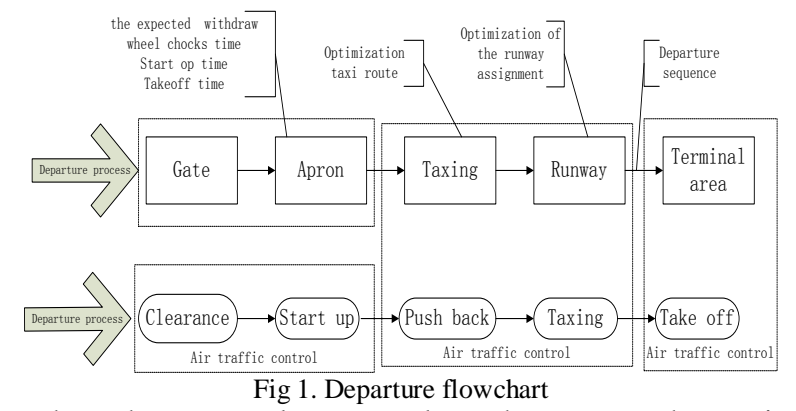

When the external system data changes, such as air traffic controller manually adjust flight plan which includes delay time of pushing back and manually adjust the departure queue, so the queue system will update data and to generate new expected departure time. The goal of departure queue is optimizing queue, rational allocation of the runway, reducing saparation and lowering the errors between planned departure time and estimated departure time ${ }^{[7]}$.

Departure queue system ${ }^{[8]}$ mainly optimized the above five processes which in order to improve departure efficiency. Departure queue system will queue the flight which base on the apron, runway and weather factors to provide more accurate time for withdrawal wheel chocks, start up, takeoff and taxi routes. With accurate withdrawal wheel chocks time, the airlines can reasonable arrange passengers' boarding time and avoid a long wait for passengers in the cabin. More accurate start up time avoids starting up in advance but not taxing and waste fuel.

According to the park position and the runway used of the departure aircraft, the system can calculate the earliest takeoff time. Based on the optimized earliest takeoff time, the system can generate departure queue ${ }^{[9]}$.

According to the statistics of the actual operation, each aircraft's taxing time from the apron to runway in Wuhan Tianhe International Airport can be entered into the database.

According to the above limitations that system generates planned takeoff time, and this time is very important. Because according to this time, we can reasonable arrange push back time and start up time. And this can display on the window of man-machine interface system. At last, it can timely give advices and tips of clearance plan. Thereby, it can avoid the aircraft which on the ground to wait for a long time and it also can reduce the possibility of forgetting to release aircraft by the air traffic controller.

Ground control ${ }^{[10]}$ is mainly responsible for aircraft to push back, start up and taxi and this process includes from 
the apron to the threshold of the runway. This phase is the busiest time which prone to delay. In order to make a smooth flight departure which requires air traffic control authorities, airlines and airports to work together. Therefore the data should be shared among the above three departments. Air traffic control authorities need to be able to give specific airline timely and the boarding gate of the airport, ground services and other information about the flight, these will contribute to the deployment, such as passenger boarding situation, the expected time to close the gate and the preparatory work before the departure time. Through a comprehensive grasp of the flight information and airport ground information, departure queue system can more accurately calculate the following data: expected time of withdrawal of block, estimated time of pushing back and starting up, estimated time of departure and taxing route. Especially, in large airports such as Wuhan Tianhe International Airport which the taxing distance is longer, by optimizing the taxi-route, it not only can reduce taxing time, but also can save a lot of fuel.

Departure flights will follow reasonable route to taxi to the threshold of the runway and the queue system will give a reasonable take-off queue. So the controller will reference this queue to give the take-off clearance.

\section{B. The departure queue system design of Wuhan Tianhe International Airport}

Entering the flight interface chart has been showed in Figure 2.

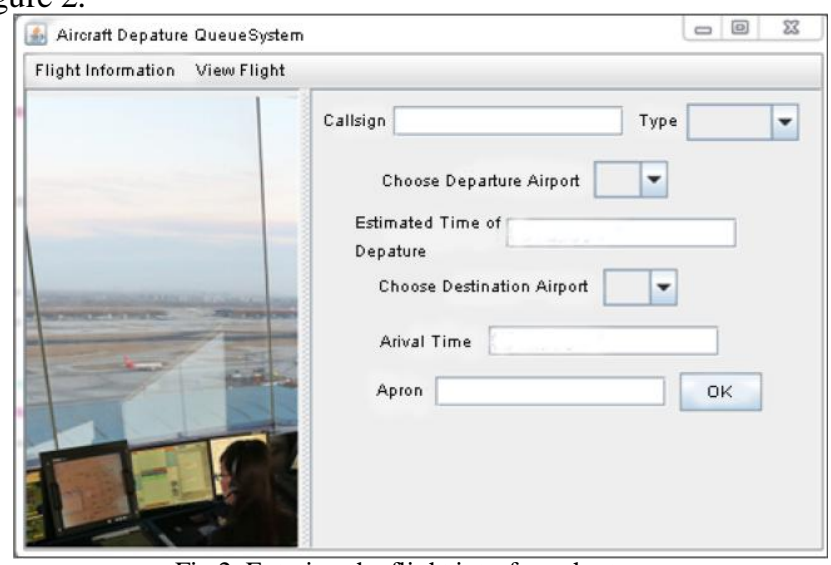

Fig 2. Entering the flight interface chart

For departure flight simulation is to generate a consistent trajectory by selecting the recorded data from the standard acceleration. The time between the front aircraft which is taking off and the one which is ready to take off must meet the relevant wake turbulence standards at least. Wake turbulence separation standards of departure is shown in Table 1. If the two aircraft are all taking off and they are all flying to the same fix, so they must satisfy a longer predetermined time interval.

TABLE I. WAKE TURBULENCE SEPARATION STANDARDS OF DEPARTURE (MINITE)

\begin{tabular}{cccc}
\hline Front aircraft afteraircraft & heavy & middle & light \\
\hline heavy & 2 & 2 & 3 \\
middle & 2 & 2 & 2 \\
light & 2 & 2 & 2 \\
\hline
\end{tabular}

\section{VERIFICATION OF ANALOG DATA}

This simulation has created a comprehensive ground track for each flight and we can get a lot of data from these tracks, such as the total taxi time in the movement area, the interval between the two takeoff aircraft and the actual departure time. To assess the accuracy of the simulation, we compare the distributions and average values between the values which in the monitoring data and the actual values.

In simulating one day in this system that we calculated the correlation value of flight, such as take-off time, the residence time in the movement area and we also compared the monitoring data in the same period. Just as mentioned in the previous section, the simulation used the timetable which was based on the monitoring data, so the system will be looking for the same set of flight for comparison.

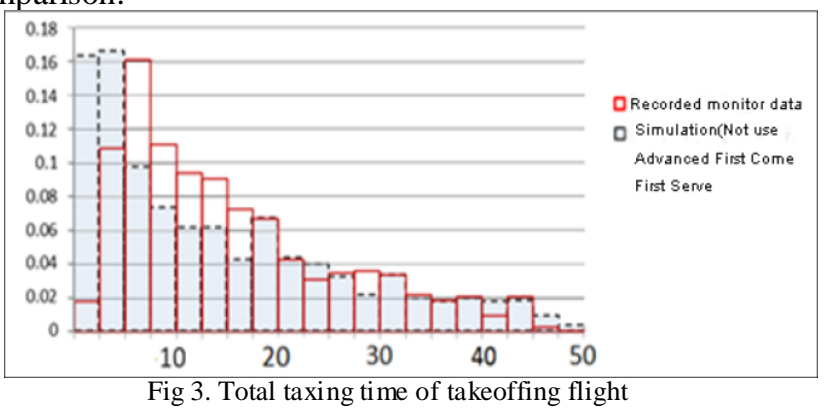

For Wuhan Tianhe Airport, the taxing out time (from entering the movement area to begin to takeoff) has been showed in Fig.3. The Fig.4 has been compared the frequency distribution of taxing out time and it is the same as which is measured in the monitoring data and model simulations. In Wuhan Tianhe Airport, we can see that it is well matched between the data and the simulation results from the shape of the distribution.

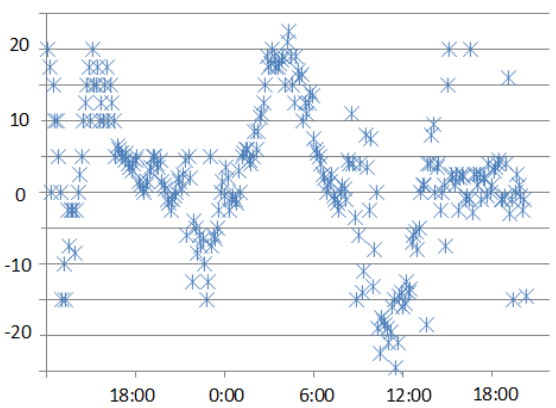

Fig 4. Takeoff Time difference: Analog-Record data

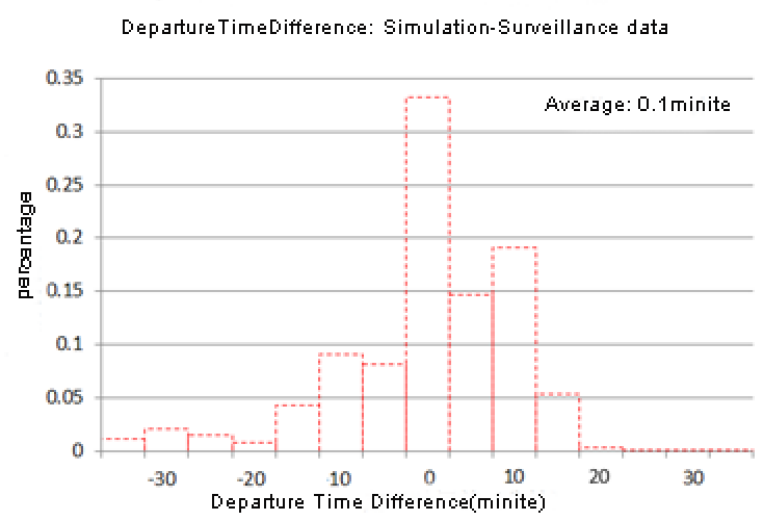

Fig 5. Comparison of actual and simulated takeoff in Wuhan Tianhe Airport 
In conjunction with Fig.4 and Fig.5, we have come to the difference of departure time in the monitoring data which has been measured in the case of first come first serve in Wuhan Tianhe Airport. In Fig.4, the difference of actual departure time among each departure is plotted as a function which is respected to the actual departure time. Figure 5 shows that the frequency distribution of the difference and its average deviation is close to zero. Thus, the simulation can accurately reflect the departure time.

In these comparisons, we can see that simulation can accurately obtain the quantitative characteristics of flight. It accurately reflects the typical taxi-out time and takeoff time.

In this simulation, we can find that the simulation results can accurately reflect the real operations of Wuhan Tianhe Airport. Therefore, when we use the improved first come first serve to simulate the airport, the difference between the two simulations will accurately describe the benefits of improved first come first serve.

We compared a wide range of values in the case that with using and unusing improved first come first serve simulations. Especially, we compared the departure queue length, departure time, taxi-out time and fuel consumption.

We also calculated the summary statistics in terms of taxing time, delay, fuel consumption. Table 2 shows the taxi-out time in movement area of Wuhan Tianhe Airport as well as the standard deviation of time before departure. So we can calculate that it is totally saved 30.2 hours of taxing time in the movement area with using improved first come first serve one day which equal to save five minutes per flight.

We also compared the total delay time that is waiting in apron area and at the movement area in Table 3. The change of departure time and the change of total delay are identical by definition. Nevertheless, the improvements that the average reduction of one minute delay corresponding the improvements of departure time is showed in Fig.10. In general, by using improved first come first serve, we can avoid delays for 11 hours. Due to improved takeoff queue to reduce delays and improve the runway throughput of 1 or 2 aircraft per hour. We can also get the important save time in Wuhan Tianhe Airport which equal to reduce two minutes delay for every departure aircraft or equal to reduce 24 hours delay one day.

TABLE II. TAXING TIME OF REDUCING IN THE MOVEMENT AREA

\begin{tabular}{cccc}
\hline & $\begin{array}{c}\text { Unused improved first } \\
\text { come first serve }\end{array}$ & $\begin{array}{c}\text { used improved first } \\
\text { come first serve }\end{array}$ & $\begin{array}{c}\text { The amount } \\
\text { of change }\end{array}$ \\
\hline sum & 97.2 & 67 & 30.2 \\
$\begin{array}{c}\text { Average } \\
\text { value }\end{array}$ & 12 & 7 & 5 \\
$\begin{array}{c}\text { Standard } \\
\text { deviation }\end{array}$ & 9 & 3 & 6 \\
\hline
\end{tabular}

TABLE III. REDUCED THE TOTAL DELAY TIME

\begin{tabular}{cccc}
\hline & $\begin{array}{c}\text { Unused improved first } \\
\text { come first serve }\end{array}$ & $\begin{array}{c}\text { used improved first } \\
\text { come first serve }\end{array}$ & $\begin{array}{c}\text { The amount } \\
\text { of change }\end{array}$ \\
\hline sum & 85 & 80 & 5 \\
$\begin{array}{c}\text { Average } \\
\text { value }\end{array}$ & 17 & 16 & 1 \\
$\begin{array}{c}\text { Standard } \\
\text { deviation }\end{array}$ & 16 & 15 & 1 \\
\hline
\end{tabular}

\section{CONCLUSIONS}

In this paper, according to the traffic flow queuing feature, considering estimate departure time, apron, wake turbulence, building simulation models to resolve the problem of terminal area capacity assessment. The assessment method is effective by example of verification, and assessment findings are more realistic. Choosing flight plan of a day to simulate the daily operation, it is totally saved 30.2 hours of taxing time in the movement area with using improved first come first serve which equal to save five minutes per flight. And we can also get the important save time in Wuhan Tianhe Airport which reduce two minutes delay for every departure aircraft or equal to reduce 24 hours delay one day.

\section{REFERENCES}

[1] ICAO ( International Civil Aviation Organization). Annex 11 to the Convention on International Civil Aviation (13th Edition)-2001 Air Traffic Services[S]. Montreal: ICAO, 2001.

[2] Kenneth Arkind. Maximum Capacity Terminal Area Operations in 2022[J]. AIAA 2003-6791.2003: 1-11.

[3] Tofukuji N. An Enroute ATC Simulation Experiment for Sector Capacity Estimation[J]. IEEE Transaction on Control Systems Technology, 1993(3):138-143.

[4] Dong Xiangning, Hu Minghua, Su Jing . Based on the terminal area capacity assessment of the ATC workload[J]. Aviation Computing Technology, 2011,41 (1): 5-8.

[5] Arad, B.A., The control load and sector design, Journal of Air Traffic Control, 1964:13-31.

[6] Siddiqee, W. A mathematical model for predicting the number of potential conflict situations at intersecting air routes, Transportation Science, 1973,7(2):571-577.

[7] Couluris, G.J. and D.K. Schmidt, Air traffic control jurisdictions of responsibility and airspace structure, in Conference on Decision and Control, 4th Annual Symposium on Adaptive Processes, Institution of Electrical and Electronics Engineers, New York, 1973:236-240.

[8] Bonnefoy Philippe,Hansman R. John.Scalability of the air transportation system and development of multi-airport systems: a world wide perspective[R].ICAT-2008-02,2008.

[9] Eugene P. Gilbo,Arrival/Departure Capacity Tradeoff Optimi zation: a Case Study at the St. Louis Lambert International Airport (STL) $[\mathrm{J}], 5$ th USA/Europe Air Traffic Management R\&D Seminar,Budapest, 2003:23 27.

[10] Buckley, E.P., DeBaryshe, B.D., Hitchener, N. and P. Kohn, Methods and measurements in real-time air traffic control system simulation, Report No. DOT/FAA/CT-83/26, Atlantic City, NJ: Federal Aviation Administration, 1983 